\title{
Diyalojik Halkla İlişkiler Boyutuyla Kamu Kurumlarında Sosyal Medya Kullanımı: T.C. Sağlık Bakanlı̆̆ı Örneği
}

\author{
Hicran Özlem ILGIN ${ }^{1}$
}

$\ddot{O} z$

Halkla ilişkiler doğası gereği iki yönlü iletişimi gerekli kılmaktadır. Bu nedenle kurum ve kamuları arasında karşılıklı gerçekleşen diyalog, halkla ilişkileri "mükemmel” boyuta taşımayı hedeflemekte ve gerçekleştirilen etkinlikleri ya da uygulamaları daha verimli kıldığı öne sürülmektedir. Bu noktalardan hareketle bu çalışma kamu kurumlarından T.C. Sağlık Bakanlığı'nın sosyal medya hesaplarını ne ölçüde diyalojik halkla ilişkiler boyutlarıyla kullandığını ortaya koymak amacıyla gerçekleştirilmiştir. Araştırmanın güncel olması nedeniyle araştırma önem taşımaktadır. Araştırmada içerik analizi yöntemi kullanılmış ve iki aşamalı olarak analiz gerçekleştirilmiştir. İlk aşamada hesapların takipçi, gönderi, beğeni, yorum ve yeniden paylaşma rakamları ve gönderi başına ortalama rakamlarının analiz edildiği ilk ölçek kullanılmıştır. İkinci aşamada ise diyalojik halkla ilişkiler ilkeleri ile oluşturulmuş 4 ana 44 alt kategoriden oluşan ölçek ile analiz gerçekleştirilmiştir. Çalışma kapsamında 1-30 Kasım 2020 tarihleri arasında kurumun Twitter, Facebook, Instagram hesaplarından paylaşılan toplam 453 gönderi analiz edilmiştir. Sonuçta hesapların bilginin kullanışlılığ boyutunda yüksek düzeyde, ziyaretin yeniden sağlanması boyutunda Twitter hesabının orta düzey, Facebook ve Instagram hesabının ise düşük düzeyde, ziyaretçilerin elde tutulması kategorisinin yüksek düzeyde ve diyaloga döngü kategorisinde orta düzeyde kendini gerçekleştirdiği verilerine ulaşılmıştır. Ayrıca çalışma sonunda takipçilerin özellikle Twitter hesabından gerçekleştirilen paylaşımlara beğeni, yorum ve tekrar paylaşım kategorilerinde daha fazla duyarlı olduğu da kayıt altına alınmıştır.

Anabtar Kelimeler: Halkla İlişkiler, Diyalojik Halkla İlişkiler, Sosyal Medya, T.C. Sağlık Bakanlığı.

\section{The Use of Social Media in Public Institutions for Dialogical Public Relations: Case of The Ministry of Health}

\section{Abstract}

Public relations require two-way communication due to its nature. For this reason, the mutual dialogue between institutions and their public is aimed at bringing the relationship to the "ideal", and it is argued that it makes the performed actions or practices more effective. Based on these points, this study was carried out at the Ministry of Health of Turkey to investigate the extent on how government agencies use their social media accounts for dialogical public relations. Research is important because the research is up-to-date. Content analysis method was used in the research and analysis was carried out in two stages. In the first stage, the first scale was used, in which the numbers of followers, posts, likes, comments and reposts of the accounts and the average numbers per post were analyzed. In the second stage, the analysis was carried out with a scale consisting of 4 main and 44 sub-categories, which was formed with the principles of dialogic public relations. Totally 453 posts shared from the organization's Twitter, Facebook and Instagram accounts between November 1-30, 2020 were analyzed in the scope of study. As a result, it was found that the accounts performed themselves at a high level in the usefulness of the information. It was found that the Twitter account performed at a medium level in terms of the re-provision of the visit, Facebook and Instagram accounts were at a low level, the visitor retention category was at a high level, and in the dialogue loop category, it was found that they performed themselves at a medium level. It has also been recorded that the followers are more sensitive to the posts made from the Twitter account in the category of like, comment and replay.

Key Words: Public Relations, Dialogical Public Relations, Social Media, T.R. Ministry of Health

\section{Atıf İçin / Please Cite As:}

Ilgın, H. Ö. (2021). Diyalojik halkla ilişkiler boyutuyla kamu kurumlarında sosyal medya kullanımı: T.C. Sağlık Bakanlı̆̆ı örneği. Manas Sosyal Araştırmalar Dergisi, 10(2), 1168-1181.

Geliş Tarihi / Received Date: 21.12.2020

Kabul Tarihi / Accepted Date: 19.02.2021

\footnotetext{
${ }^{1}$ Dr. Öğr. Üyesi. - Çanakkale Onsekiz Mart Üniversitesi Ezine Meslek Yüksekokulu, hicranilgin@comu.edu.tr

(iD ORCID: 0000-0002-0549-0710
} 


\section{Giriş}

İnternetin, kuruluşların temel paydaşlarıyla ilişki kurma şeklini değiştirmeye başladığı bir sürecin içindeyiz. Halkla ilişkiler bir şekilde geleneksel taktiklere dayansa da, sosyal medya uygulamaları gibi teknoloji tabanlı birçok araç ile uygulamalarını şekillendirmeye ve bu yeni olanaklara uygun stratejiler oluşturmaya uygulamacıları yönlendirmeye başladı. Geleneksel medyadan farklı olarak sosyal medya iki yönlü ve görece-etkili bir ortam sunmakta ve halkla ilişkileri profesyonel olarak uygulamak isteyen uzmanlar yeni medya olanaklarını değerlendirmektedir. Dijital medyanın diyalojik, etkileşimli, ilişkisel ve küresel özellikleri, onları halkla ilişkilerin stratejik bir yönetim paradigması için mükemmel bir şekilde uygun hale getirmelerine olanak sağlamaktadır. İnternet kullanımı ve sosyal medya uygulamaları gibi teknolojik yenilikler, çevrimiçi ilişkiler kurmak ve diyalojik iletişim gerçekleştirmek için kullanılabilecek birer araç olduğu artık bilinmektedir.

Bu noktalardan hareketle bu araştırmanın konusu kamu kurumlarından T.C. Sağlık Bakanllğı'nın sosyal medya kullanımlarının ne ölçüde diyalojik halkla ilişkiler boyutuyla kullanıldığıdır. Bu araştırmanın amacı ise T.C. Sağlık Bakanlığı'nın sosyal medya hesaplarını diyalojik halkla ilişkiler boyutuyla ne ölçüde kullandığını ortaya koymaktadır. Bu noktadan hareketle bakanlığın sosyal medya hesapları diyalojik halkla ilişkiler ölçeği ile bilginin kullanışlılığı, ziyaretin yeniden sağlanması, ziyaretçilerin elde tutulması, diyaloga döngü kategorilerinde analiz edilerek alan yazına güncel bir durum analizi kazandırılması hedeflenmektedir. İnternetin her gün değişen ve gelişen doğasından hareketle çalışmanın güncel olması çalışmanın önemini ortaya koymaktadır. Diğer yandan çalışmanın gerçekleştirildiği dönemin Covid 19 pandemi dönemi olması bakanlığının hesaplarının da aktif olarak kullanıldığı bir dönem olarak öngörüldüğü de belirtilmelidir. Çalısmada önce diyalojik halkla ilişkilere ilişkin, daha sonra kamu kurumlarında sosyal medya kullanımlarına ilişkin yazına yer verilecektir. Araştırmanın yönteminin açıklanmasından sonra bulgular ve ardından sonuç ve tartışma içinde çalışma detaylandırılacaktır.

\section{Diyalojik Halkla İlişkiler Ve İlkeleri}

Türk Dil Kurumu Güncel Türkçe sözlüğe göre diyalog, karşıllklı konuşma anlamına gelmektedir. Diğer bir anlam olarak anlaşma, uyum sağlama ve bu yolda çalışma anlamı taşımaktadır (https://sozluk.gov.tr/). Buna göre diyalojik halkla ilişkilerde öncelikle yüz yüze gerçekleştirilen ve uyum sağlama diyaloglar işaret edilirken bugün gelen boyutuyla kamunun dileklerini dinleme ve anlaşma, uzlaşma sağlanarak paydaşlarla aynı anda fayda elde etme anlamı taşımaktadır. Diyalojik halkla ilişkiler ile simetrik iki yönlü bir halkla ilisskiler modelinden bahsedilmekte ve bu model Basın Ajansı modeli, Kamuyu Bilgilendirme Modeli gibi sadece bilgilendirme tabanı üzerinden tek yönlü ifadesinden çıkmakta, geri bildirimi mümkün kılan ve iki yönlü değişimi ve uyumu işaret eden bir model olarak karşımıza çıkmaktadır. İki yönlü simetrik modele benzeyen bu yaklaşım ile Grunig’in (2005, s. 314) ifadesiyle iki yönlü iletişim içeren simetrik halkla ilişkiler modeli mükemmeli işaret etmektedir ve kurumların etkinliğine en büyük katkıyı bu model sağlayacaktır. Bu modelin de temelinde diyalog ve karşlıklı etkileşimden söz edilmektedir.

Diyalojik Model, paydaşlar arasında eşitliği ve adaleti korumaya çalışır. Diyalojik kuruluşların amacı, sadece yönetimsel hedefleri hayata geçirmek değil, aynı zamanda paydaşların ihtiyaçlarını izlemektir. Diyalojik iletişimciler, kuruluşun çıkarları ile kilit paydaşları arasında arabuluculuk yapar ve etkilemek veya bağlı kalmak yerine karşılıklı anlayış arayışı içinde yer alır (Kent ve Taylor, 1998, 2002'dan akt. Kent ve Taylor, 2011, s. 55). Yönelim olarak bu diyalog beş özelliği içerir; karşllklllık veya organizasyon-kamu ilişskilerinin tanınması; yakınlık veya etkileşimlerin geçiciliği ve kendiliğindenliği, halkla; empati veya kamu hedeflerinin ve çıarlarının desteklenmesi ve doğrulanmasi; risk veya bireyler ve paydaşlarla kendi şartlarına göre etkileşim kurma istekliliği; ve sonunda, bağlllık veya bir kuruluşun diyaloğa, yoruma ne ölçüde kendini vermesi ve halkla etkileşimlerinde anlayış olarak sıralanır. Bu ilkeler, diyalog kavramının alında yatan örtük ve açık varsayımları kapsamaktadır. Kent ve Taylor bu noktada oluşturdukları listenin kapsamlı olmadığına ve kavramlar arasında doğal olarak bazı örtüşmelerin meydana geldiğine dikkat çekmektedir. Onlara göre diyalog iletişimsel bir "yönlendirme" olduğundan ve bir dizi kural olmadığından, özellikler arasında bazı örtüşmeler beklenmektedir (Kent ve Taylor, 2002, s. 27-28). Bu özellikler diyalojik halkla ilişkilerin anlaşılabilmesi için önem taşımaktadır. Temel taşları; ortaklık, yakınlık, empati, risk ve bağılık üzerine kurulan ilkeler diyalojik halkla ilişskileri oluşturmaktadır.

Kent ve Taylor'de (1998) gerçekleştirdikleri çalsşmada diyalojik halkla ilişkilerin temellerini atarak iletişimcilerin ilgisini bu yöne çekmiştir. Halkla ilişkilerin diyalojik boyutunu teşvik eden model, web sitelerinin etkileşime olanak sağlayan yüzü ile bir araya geldiğinde yeni bir kullanım alanı ortaya çıkmışırı 
(Rybalko ve Seltzer, 2010, s. 337). Çalışmalarında diyalojik halkla ilişkilerin ilkelerini ortaya koyduğu ve bu noktadan hareketle bu ilkeleri temel alan web sitesi analizleri ve sosyal medya analizi çalışmalarının (Seltzer ve Mitrook, 2007, s. 227-229, Rybalko ve Seltzer 2010, s. 336- 441, Özdemir ve Yamanoğlu 2010, s. 3-36, Boztepe 2013, s. 110-128, Türkal ve Güllüpınar 2017, s. 591-618, Arslan, 2019, s. 84-98 ) ulusal ve uluslararası yazında yer aldığı görülmektedir. Diğer yandan diyalojik halkla ilişkilerin çevrimiçi yaklaşımına eleştirel yaklaşan çalışmalar (Artan Özoran, 2017, s. 1-30) da alan yazında yer almaktadır.

Kent ve Taylor (1998, s. 321-331), diyalojik halkla ilişkileri web siteleri üzerine uyarlarken beş ilkeden bahsetmektedir. Bu ilkeler; diyalojik döngü, enformasyonun kullanışlllı̆ı, yeniden ziyareti sağlama, ara yüzün kolaylı̆̆1, ziyaretçilerle sohbet olarak sıralanmaktadır. Diyalojik döngü ilkesinde simetrik iletişim diğer deyişle karşıllk, çift yönlü iletişim ifade edilmektedir. Kurumun içinde kurumu ifade edebilecek kurum adına kurum politikalarına uygun biçimde kişilerden gelecek soruları yanttlayabilecek internet bağlantı kişilerinin belirlenmesine işaret etmektedir. İkinci ilke ise verilen enformasyonun kullanışlilığıdır. Buna göre kamuya sunulan bilgi diyalojik ilişki için faydalı ve güvenilir olmalıdır. Diğger yandan kamular ile kurulacak ilişkide kamunun endişelerinin giderilmesi, sorularının yanıtlanması beklenir. Diğer yandan oluşacak diyaloglarda kamu ve kurumun bütünleşmesi hedeflenir. Üçüncü ilke yeniden ziyareti sağlama ilkesidir. Kent ve Taylor'a göre internet siteleri oluşturulurken ziyaretçilerin tekrar ziyaret etmesini sağlayacak biçimde tasarlanmalıdır. Dördüncü ilke ara yüzün kullanışlılığıdır diğer bir deyiş ile ziyaretçilerin kolay kullanabileceği bir yapıda oluşturulmuş internet sitesine işaret eder. Son ilke ise ziyaretçilerin siteyi ziyaret sürelerini uzatmak için internet sitesini kullanıcılarının ilgisini çekecek nitelikte öğeler kullanılmalı ve sadece zorunlu durumlarda başka sitelere link vermelidir (Kent ve Taylor, 1998, s. 327-331). Bu ilkeler doğrultusunda ara yüzün kullanışlilığı sosyal medya uygulamalarında tek tip ara yüz bulunması nedeniyle analiz ölçeğinde kullanılmayacaktır.

Modele eleştirel bir bakış açısıyla yaklaşıldığında ise hızın önem kazandığı bir dönemde halkla ilişkiler için internetin önemli bir hale gelmesi ve 'Kamularla' hızlı bilgi akışının sağlanması ve geri bildirim alınması hayati bir öneme sahip olduğuna dikkat çekilmiştir. Bu nedenle halkla ilişkilerin hayati bir araç haline gelmesi ve yeni iletişim teknolojilerinin bu iletişimi kurmanın etkili bir aracı olduğu işaret edilirken bu koşullar altında örgütlerin 'diyalojik halkla ilişkiler' yaklaşımını benimsemek isteyip, istemedikleri önemli bir sorun alanı olarak ortaya çıkaracağı öne sürülmektedir (Özoran, 2017, s. 21).

Diyalog ilişki kurmanın temel unsurlarındandır. Diyalog kurma kurumsallaştırılan iki yönlü iletişim modeliyle benzemektedir. Diyalog hedef kitleler ile karşllıklı yarar ilişkilerini sürdürmek ve geliştirmek için gereklidir. Diyalog farklı görüsslere değer vermek anlamına gelmektedir. İki yönlü simetrik iletişime dayanan diyalogu geliştirmenin amacı hedef kitlenin kurumsal bağlllı̆ını kazanmak için sosyal medyanın bir araç olarak kullanılmasıdır. Sosyal medya bu noktada diyalog açısından kurum ve kuruluşlara şeffaf bir ortam sağlamaktadır (Çelebi, 2019, s. 79). Çalışmanın eksenini oluşturan sosyal medyada halkla ilişkiler kavramı bu noktalardan hareketle diyalojik halkla ilişkiler çerçevesinde değerlendirilecektir.

\section{Resmi Kuruluşlarda Halkla İlişkiler Aracı Olarak Sosyal Medya Kullanımı}

Yeni medya, bilgisayar ve iletişim teknolojileriyle ortaya çıkan, kullanıcıların diledikleri yer ve zamanda başkalarıyla etkileşim içerisine girdikleri sanal medya ortamlarıdır (Bulunmaz, 2011, s. 23-27). Geniş kitlelere kısa zamanda iletişim imkânı veren, sınırları ortadan kaldıran ve mesafeleri daraltan özelliğiyle yeni medyayı da halkla ilişkiler yöntem ve araçları içine dâhil etmiştir. Sosyal medyanın geniş çaplı paylaşım özelliği sunan teknolojisi iletişimin hızını saliselere indirmekte ve yeni teknoloji cihazlarla sosyal medyayla olan ilişkiler yoğunlaşmakta, Facebook ve Twitter gibi ağlar halkla ilişkiler kanalı haline dönüşmektedir. Sosyal medyanın özellikleri kurum ile hedef kitle arasında bağllliğı oluşturma görevini yerine getirmektedir (Peltekoğlu, 2012, s. 322-323, Budak ve Budak, 2014, s. 299). Sosyal medya platformları halkla ilişkiler uygulayıcıları için hedef kitle uygulamalarına yönelik olarak pratik yöntemler ortaya koymaktadır ve hatta uygulayıcılar için sosyal medya hedef kitleleriyle iletişim kurmada en etkili araç olarak görülmektedir (Çelebi, 2019, s. 74). Kullanılan medya monoloğu, internet ve web-in dönüşümü sosyal medya ile iki yönlü konuşmaya (Breakenridge ve Solis, 2009, s. 180) dönüşmüştür. Sosyal medyanın etkileşimli kolaylaştırma özelliği geleneksel halkla ilişkiler iletişimi araçlarına göre olumlu bir özelliktir. Hedef kitle bilgiyi faydalı bulduğunda etkileşime geçecektir (Çelebi, 2019, s. 85). Bu noktada halkla ilişkiler uygulayıcısının sosyal medya içeriklerini üretirken kullanıcı etkileşimini artıracak nitelikte paylaşımlar gerçekleştirmesi önem duyulan bir noktaya dönüşmektedir.

Sosyal ağ siteleri toplulukların katılımcıların ortak ilgi alanlarına göre oluşabileceği çevrimiçi alanlardır. $\mathrm{Bu}$ araç sayesinde, hükümetler, bir politikaya özel yeni bir ağ veya web sitesi oluşturmaya çalışmaktan daha 
verimli ve uygun maliyetli bir seçenek olan mevcut sosyal ağlardan yararlanma firsatına sahip olur. Profil oluşturma ve bilgi gönderme imkânlarını sunan kullanıcı dostu bir uygulamalardır (McNutt, 2012, s. 3). Devlet kurumlarının sosyal medya kullanarak kamuyla etkileşim halinde olması, bu platformlarda kurumlar tarafindan tanitılan ve hakkında bilgi verilen politikaların kamuoyu nezdinde kabul kazanmasına olumlu etki etmektedir (Bergquist, Ljungberg, Remneland, and Rolandsson, 2017, s. 859). Artan sosyal medya kullanımı, hem politika analizi için bir dizi aracı hem de bir dizi politika sorununun ortaya çıkmasını temsil etmektedir. Bir yandan, "World Wide Web", bilginin geniş sosyal ağlarda yayılmasını kolaylaştırır; öte yandan, bu ağlar sosyal hayatı hükümetin dikkatini gerektiren şekillerde değiştirmiştir. Yeni medya, sıradan vatandaşların, Bakanlara yorumları doğrudan "tweet atmasına" izin vermektedir; bu da aynı zamanda güçlü geniş bant bağlantısına sahip alanlarda bulunanların, olmayanlara göre bir avantaja sahip olduğu anlamına gelir. Dijital formatlar, hükümetlerin bilgiyi daha açık bir şekilde paylaşmasını kolaylaştırmaktadır. Bazıları bunu "açık hükümet" olarak adlandırmaktadır. Bununla birlikte, bu bilginin yorumlanması, toplum üzerindeki etkileri hakkında anlamlı bir yorum sağlayacak uzmanllğa ve / veya uygun derecede güvene sahip olunması gerekmektedir. Sosyal medyanın hükümet tarafindan nasıl kullanılabileceği ve bu konuda hükümetin ne yapması gerektiği 21. yüzyll kamu sektörü için temel sorulardır (McNutt, 2012, s. 12). Sosyal medyaya atfedilen kayıt dışılı ile kamu otoritesinin kullanılmasıyla bağlantılı formalite arasında gerilim yaratılması muhtemeldir. Bu ikili yön, bir yandan kamu kuruluşları ve vatandaşlar arasında artan meşruiyet olasıllkları yaratırken, diğer yandan bir kamu kurumu için neyin uygun görüldüğü konusunda dengeler yaratır (Bergquist, Ljungberg, Remneland ve Rolandsson, 2017, s. 859). Bu nedenle sosyal medya hesaplar1 üzerinden kamuyla iletişime geçen halkla ilişkiler uygulayıcılarının kurumun temel politikalarını özümsemiş ve stratejik bir iletişim planını uygular durumda olması gerekmektedir.

Alan yazında T.C. Sağılı Bakanlığı’nın sosyal medya kullanımının araştırıldığı (Erkek, 2016, s. 141150), T.C. Spor Bakanlığı'nın sosyal medya kullanımın incelendiği (Kalfa ve Adaş, 2016, s. 8-21), T.C. Sağlık Bakanlığı ve bakanının paylaştığı görsellerin analizinin gerçekleştirildiği (İşleri ve Tekin, 2020, s. 559581), kamu yönetiminde kullanılan sosyal medya uygulamalarının incelendiği (Yağmurlu, 2011, s. 5-15), T.C. Turizm Bakanlığı sosyal medya hesaplarının analiz edildiği (Duğan ve Aydın, 2018, s. 1-13) gibi birçok çalışma bulunmaktadır. Ayrıca T.C. Sağlık Bakanlığı'nı pandemi döneminde ele alan Kalçık ve Bayraktar'ın (2020, s. 583-602) Sağlık Bakanı'nın Twitter hesabının analiz edildiği, T.C. Sağlık Bakanlığı’nın Youtube hesabının pandemi dönemi analizinin geçekleştirildiği (Kartal, Dağ ve Taşan, 2020, s. 122-130) çalışmalar da alan yazında yer almaktadır.

Tüm bu sıralanan noktalardan hareketle bu çalısmanın konusunu T.C. Sağlık Bakanlığı’nın resmi sosyal medya hesaplarının ne ölçüde diyalojik halkla ilişkiler boyutunda kullanıldığının incelenmesi oluşturmaktadır. Çalışmanın yapıldığı dönemin Covid 19 pandemisi döneminde olması nedeniyle sosyal medya hesaplarının aktif olarak kullanıldığı ön görülmektedir. Kamu ile iletişimde önemli bir araç olan sosyal medya aynı zamanda uzmanlaşmayı ve stratejik iletişim süreçlerini gerektiren bir alan olarak uygulayıcılar tarafından değerlendirilmektedir. Bu nedenle alanda yapılan bu ve benzeri çalışmaların uygulayıcılar için sşık tutması araştırmaların hedefleri içinde yer almaktadır.

\section{Yöntem}

Bu çalışma T.C. Sağlık Bakanlığı resmi Twitter, Facebook ve Instagram hesabının diyalojik halkla ilişskiler boyutuyla incelenmesini konu almaktadır. Araştırmanın amacı ise T.C. Sağlık Bakanlığı'nın sosyal medya uygulamalarını, etkileşimi temel alan diyalojik halkla ilişkiler boyutunda ne ölçüde kullandığını ortaya koymaktır. Bu doğrultuda araştırmanın soruları şu şekildedir:

1. T.C. Sağlık Bakanlığ1 sosyal medya hesapları aktif olarak kullanılmakta mıdır?

2 T.C. Sağlık Bakanlığı Twitter hesabı üzerinde diyalojik halkla ilişkiler ilkelerini ne düzeyde gerçekleştirebilmektedir?

3 T.C. Sağlık Bakanlığı Facebook hesabı üzerinde diyalojik halkla ilişkiler ilkelerini ne düzeyde gerçekleştirebilmektedir?

4 T.C. Sağlık Bakanlığı Instagram hesabı üzerinde diyalojik halkla ilişkiler ilkelerini ne düzeyde gerçekleştirebilmektedir?

5 Takipçiler T.C. Sağlık Bakanlığı’nın Twitter gönderilerine ne ölçüde etkileşim göstermektedir?

6 Takipçiler T.C. Sağlık Bakanlı̆̆ı'nın Facebook gönderilerine ne ölçüde etkileşim göstermektedir?

7 Takipçiler T.C. Sağlık Bakanlı̆̆ı'nın Instagram gönderilerine ne ölçüde etkileşim göstermektedir? 


\section{Araştırmanın Örneklemi}

Bu çalışma T.C. Sağlık Bakanlığı’nın sosyal medya hesaplarını ele almaktadır. Bu noktada analiz için araştırmanın yapıldığı döneme en yakın tarih kesiti olarak 1-30 Kasım 2020 tarihleri arasında resmi Twitter, Facebook ve Instagram sayfasından paylaşılan gönderiler araştırma örneklemini oluşturmaktadır. Araştırmanın öneminin güncel olmasından hareketle araştırmaya en yakın tarih seçilerek 1-30 Kasım 2020 tarihleri arası olarak belirlenmiştir. Araştırma verileri geriye dönük olarak 1-8 Aralık tarihleri arasında analiz edilmiştir. Buna göre sosyal medya hesaplarının temel verilerini yanı sıra etkileşim oranlarını elde edebilmek amaciyla Twitter'da 218, Facebook'ta 183, Instagram'da 52 gönderi olmak üzere 453 içerik örnekleme dâhil edilmiştir.

\section{Veri Toplama Araçları}

$\mathrm{Bu}$ araștırmanın yöntemi içerik analizidir. İçerik analizi bir takım aşamalar halinde gerçekleştirilmelidir. Belirli konuda çalışmak isteyen araştırmacı ilk aşamada araştırma hedeflerini belirlemelidir. İkinci aşama ise örneklemin oluşturulmasıdır. İçerik analizinin örneklemi, incelenecek iletişimlere bağlı olarak gazete, dergi, öykü, film ve diğer iletişim araçlarından oluşabilir. Üçüncü aşamada örneklemin bölüneceği birimler maddeler ya da kayıt birimleri ve bunların içinde toplanacağı kategoriler belirlenmelidir (Bilgin, 2016, s. 11). Kent ve Taylor'un (1998) ortaya koyduğu diyalojik halkla ilişkiler ilkeleri temel alınarak kategoriler oluşturularak içerik analizi gerçekleştirilmiştir. Bu noktada bahsi geçen ikinci aşamada Türkal ve Güllüpınar'n (2016) 'Diyalojïk Halkla İlișkiler Bağlamında Sosyal Medya Kullanımı: Türkiye'de İlk 100'de Yer Alan Şirketler Üzerine Bir İnceleme" çalışmasında geliştirdiği ölçek kullanılmıştır. Diğer yandan ölçeğin kamu kurumu sosyal medya hesaplarına yönelik oluşturulması nedeniyle gerek görülen bazı söylemler değiştirtilmiştir. Örnek olarak örgüt yerine kurum, kullanıcı yerine takipçi söyleminin kullanılması verilebilir. Ölçekte kullanılan temel kategoriler; bilginin kullanışllığı kategorisi, ziyaretçilerin elde tutulması kategorisi, yeniden ziyaretin sağlanması kategorisi, diyalojik döngü kategorisi olarak sıralanmaktadır. Ölçeğe ilişkin bir diğer eklenti ise diyalojik döngü kategorisinde yer alan kodların yanı sıra belirlenen sosyal medya hesaplarının belirlenen tarihler arasında gerçekleştirdiği paylaşımlara takipçilerin beğeni, yorum ve tekrar paylaşım oranını koymak amacıyla veriler kayı altına alınmış ve takipçi etkileşimleri diyalojik döngü içinde değerlendirilmiştir.

Araştırmada bunun yanı sıra belirlenen süre içinde analiz edilen hesapların gönderi rakamları, içerik beğeni rakamları, yorum sayıları, tekrar paylaşılma/retweet sayıları da kayıt altına alınmıştır. Bu noktadan hareketle aşağıdaki formül kullanılarak gönderi başına takipçi etkileşimi ortaya konulmuş ve detaylandırılmıştır.

$$
\frac{\text { Toplam Beğeni Sayısı }}{\text { Toplam Gönderi Sayısı }}=\text { Gönderi Başına Beğeni Etkileşim Sayısı }
$$

$$
\frac{\text { Toplam Yorum Sayısı }}{\text { Toplam Gönderi Sayısı }}=\text { Gönderi Başına Yorum Etkileșim Sayısı }
$$

\section{$\frac{\text { Toplam Paylaşım(Retweet) Sayısl }}{\text { Toplam Gönderi Sayısı }}=$ Gönderi Başına Paylaşım Etkileşim Sayısı}

"Diyalojik Halkla İlişkiler İlkeleri” temel alınarak oluşturulan kategoriler ile gerçekleştirilen içerik analizleri iki kodlayıcı tarafindan gerçekleştirilmiş ve güvenirlik düzeyi Cohen's Kappa formülü ile denetlenmiştir. Buna göre Facebook için 42 kodlama ölçütü üzerinden 42 ölçüt üzerinde aynı sonucu elde etmişlerdir. Buna göre $\mathrm{K}=42 / 42, \mathrm{~K}=1$ güvenilirlik düzeyine ulaşmışlardır. Twitter kodlama ölçütleri üzerinden 42 ölçüt üzerinden 41 kriteri aynı kodlamışlardır. Buna göre Twitter kodlama güvenirlik düzeyi $\mathrm{K}=41 / 42, \mathrm{~K}=0.98$ güvenirlik düzeyi kaydedilmiştir. Instagram kodlama ölçütleri üzerinde ise $42 \mathrm{kod}$ üzerinden 42 ölçüt üzerinde aynı sonuca ulaşarak Cohen Kappa indeksine göre K=1 güvenirlik düzeyi elde edilmiştir. Kodlama kullanılan ölçüt için kişisel yargılara müsaade etmeyecek biçimde oluşturulmuş olan ölçekte var veya yok yanıtı ile 1-0 olarak analiz gerçekleştirilmiştir. İki kodlayıcının ayrı düştüğü Twitter kodlamasındaki tek ölçüt için tekrar değerlendirme gerçekleştirilmiş ve fikir birliğine varılmıştır. Çalışmanın kodlamasının güvenirlik düzeyi Leiva vd.'ne göre, (2006, s. 523) çok iyi olarak değerlendirilmektedir. 


\section{Bulgular}

Çalışmanın bu bölümde analiz edilen veriler iki ayrı tablo ile değerlendirilecektir. İlk tablo hesapların takipçi, takip, gönderi sayıları ve hesap açılış tarihleri ile beğeni, yorum, paylaşım sayıları ve gönderi başına ortalama beğeni, yorum ve paylaşım sayılarını içeren tablodur. İkinci tabloda diyalojik halkla ilişkiler ilkelerinden hareketle hazırlanmış olan ölçüt tablosu içinde veriler verilecektir. Ayrıca T.C. Sağlık Bakanlı̆̆1 sosyal medya hesaplarından yapılan paylaşımlara ilişkin örnekler ile bakanlığın sosyal medya hesaplarının diyalojik halkla ilişkiler boyutu değerlendirilerektir.

T.C. Sağlık Bakanlığı Resmi Twitter hesab1 analizinin gerçekleştirildiği tarihte 1.970 .051 takipçi ve 21 takip ettiği hesap sayısı kayıt altına alınmıştır. Hesaptan açılış tarihinden itibaren paylaşılan tweet sayısı 18.000 yaklaşık değer olarak görülmektedir. Hesap Nisan 2012 tarihinde açılmıştır. Facebook doğası gereği kullanıcı hesabı açmadan sayfa açmaya imkân sağlaması nedeniyle T.C. Sağlık Bakanlığı'nın resmi sayfası olarak Facebook'ta yer almaktadır. Bu hesap Nisan 2012 tarihinde açılmış ve 1.763 .835 takipçi rakamına sahiptir. Sayfada takip gerçekleştirilemediğinden ve paylaşılan gönderi rakamları yer almadığından kayıt sağlanmamıştır. Instagram hesabında ise toplam olarak 3.162.880 takipçi, 9 takip ve 1198 toplam gönderi sayısı kaydedilmiştir. Hesap aç1lıs tarihi ise sayfada yer almamaktadır.

Tablo 1. 1-30 Kasm 2020 Taribleri Arasinda Twitter, Facebook ve Instagram Verileri

\begin{tabular}{|c|c|c|c|}
\hline 1-30 Kasim 2020 & Twitter & Facebook & Instagram \\
\hline Takipçi Sayıları & 1.970 .051 & 1.763 .835 & 3.162 .880 \\
\hline Takip Sayıları & 21 & ------- & 9 \\
\hline Gönderi Sayıları & 18.000 & ----- & 1.198 \\
\hline Hesap Açılış Tarihi & Nisan 2012 & Nisan 2012 & ------ \\
\hline Gönderi/Tweet Sayıs1 & 218 & 183 & 52 \\
\hline Toplam Beğeni Sayısı & 3.233 .271 & 436.587 & 624.143 \\
\hline Toplam Yorum Sayıs1 & 174.110 & 13.791 & 11.030 \\
\hline Paylaşım/Retweet Sayısı & 307.248 & 29.343 & ------ \\
\hline Gönderi Başına Ortalama Beğeni Sayısı & 14.832 & 2.386 & 12.003 \\
\hline Gönderi Başına Ortalama Yorum Sayısı & 799 & 75 & 212 \\
\hline Gönderi Başına Ortalama Paylaşım Sayısı & 1409 & 160 & ------- \\
\hline
\end{tabular}

Analizin gerçekleştirildiği 1-30 Kasım tarihleri arasında Twitter'da 218, Facebook'ta 183, Instagram'da 52 gönderi paylaşılmıştır. Twitter'da paylaşılan 218 gönderiye toplam olarak 3.233.271 beğeni, 174.110 yorum ve 307.248 geri paylaşım kayıt altına alınmıştır. Buradan hareketle hesabın paylaştığı gönderilen başına 14.832 beğeni, 799 yorum, 1.409 tekrar paylaşma sayısına ulaşılmıştır. Facebook'ta toplam 183 gönderi paylaşılmış ve 436.587 beğeni, 13.791 yorum, 29.343 tekrar paylaşım sayısı kayıt altına alınmıştır. Bu noktadan hareketle hesabın bahsi geçen dönem içinde gönderi başına beğeni sayısı 2.386, yorum sayıs1 75 ve tekrar paylaşım sayısı 160 olarak hesaplanmıştır. Instagram'da ise toplam 52 gönderiye 624.143 beğeni, 11.030 yorum ve gönderi başına ortalama beğeni 12.003, yorum sayısı 212 olarak kayıt altına alınmıştır. Instagram uygulaması geri paylaşım imkânını kendi uygulaması içinde vermediği için geri paylaşım sayısı Instagram'da yer almamaktadır.

Twitter ve Facebook takipçi sayıları birbirine çok yakın olmasına rağmen gönderi başına gerçekleşen beğeni, yorum ve tekrar paylaşım rakamları farkllılı göstermektedir. Bu veriler 1şı̆̆ında Twitter kullanııılarının beğeni, yorum ve tekrar paylaşım yapması noktasında Facebook kullanıcılarından daha duyarlı olduğunu söylemek mümkündür.

Diyalojik Halkla ilişkiler ölçütleri üzerinden yapılan analiz sonuçlarını içeren tablolar aşağıda yer almaktadır. Buna göre toplam 44 soruda 3 sosyal medya hesabındaki toplam 453 gönderi analiz edilerek aşağıdaki veri tablolarına aktarılmıştır. Bu noktada ilk kategori olan bilginin kullanışlılı̆ı kategorisi; profil bilgileri boyutu, kamu kurumları için bilginin yararlllığ boyutu ve medya için bilginin yararlllı̆̆ boyutu olarak alt kategorilerde değerlendirilmiştir. Buna göre profil bilgileri boyutu Twitter için \%89, Facebook için \%100, Instagram için \%89 olarak kayıt altına alınmıştır. Burada sosyal medya hesaplarında oluşan farkın Facebook uygulamasında etkinlikler sayfasının bulunması ve diğer uygulamalarda ise sayfa seçeneğinin olmamasından kaynaklanmaktadır. Bu noktada her bir sosyal medya hesabının künyesinin kurumsal kimliğe uygun biçimde hazırlandığının söylenmesi yerinde olacaktır. Kurum kamuları için yararlı bilgiler kategorisinde ise Twitter \%40, Facebook\%60, Instagram \%40 olarak belirlenmiştir. Bu noktada analiz gerçekleştirilen hesapların kamu kuruluşu olması gerekçesiyle vizyon misyon gibi bilgilerin sosyal 
medya hesabı künyesinde yer almadı̆̆ı ve takipçilerin mesajlarının paylaşılmadığı düşünülebilir. Kurumun kamuları için yararlı bilgiler kategorisine örnek olarak tablolardan sonra Resim 1 ile bir önek paylaşılmıştır. Diğer yandan kurumun kariyer olanaklarına ilişkin tek bir paylaşımı Facebook üzerinde kaydedilmiştir. Sağlık Bakanlığı'nın personel alımına ilişkin içerik aşağıda detayları verilen örnekler içinde Resim 2 olarak yer almaktadır. Bilginin kullanışlılığı kategorisinde yer alan son alt kategori medya için bilginin yararlılı̆̆ boyutunda Twitter \%100, Facebook \%100, Instagram \%100 olarak kaydedilmiştir. Bu k1simda kategori yüzdeleri olarak değerlendirilen her alt ölçüte ilişkin detaylara aşağıda yer alan tablodan ulaşılabilir. Bilginin kullanışl1lı̆̆ kategorisinde toplam standart sapma ise Twitter \%76, Facebook \%87, Instagram ise $\% 86$ olarak hesaplanmıştır. Buna göre bilginin kullanışlılı̆̆1 kategorisinde bakanlığın sosyal medya hesaplarının yüksek düzeyde gerçekleştirildiğini söylemek mümkün olmaktadır.

Tablo 2. Bilginin Kullanıshlilı̆̆ Kategorisi

\begin{tabular}{|c|c|c|c|c|}
\hline & Bilginin Kullanışlılı̆̆1 Kategorisi & Twitter & Facebook & Instagr \\
\hline \multicolumn{5}{|c|}{ Profil Bilgileri Boyutu } \\
\hline 1 & Profil Fotoğrafi / Logo & Var & Var & Var \\
\hline 2 & İsim (Kurumun ismi) & Var & Var & Var \\
\hline 3 & Kapak Fotoğrafi & Var & Var & Var \\
\hline 4 & Resmi Web Sitesi Adresi & Var & Var & Var \\
\hline 5 & $\begin{array}{llll}\text { Biyografi Bölümü (Kurumun } & \text { Kendini } & \text { Tarifi, } \\
\text { Adresinin İslevi Hakkında Bilgi ve Profil kimin } & \text { ve }\end{array}$ & Var & Var & Var \\
\hline 6 & $\begin{array}{l}\text { Kurumun Diğer İletişim ve Sosyal Medya Adresleri } \\
\text { (E-posta Telefon Numaras1, Twitter, Youtube vb.) }\end{array}$ & Var & Var & Var \\
\hline 7 & Beğenen Bilgisi & Var & Var & Var \\
\hline 8 & Etkinlikler Sayfası & Yok & Var & Yok \\
\hline \multirow[t]{3}{*}{9} & Hizmetlerle İlgili Uygulamalar & Var & Var & Var \\
\hline & Yüzde & $\% 89$ & $\% 100$ & $\% 89$ \\
\hline & Kurum Kamuları İçin Bilginin Yararlılığı Boyutu & & & \\
\hline 1 & $\begin{array}{l}\text { Kurum Hakkında Bilgi İçeren Mesajlar (Vizyon, } \\
\text { Misyon Felsefe vb) }\end{array}$ & Yok & Yok & Yok \\
\hline 2 & Takipçilere Dönük Yararlı, Güncel Bilgiler & Var & Var & Var \\
\hline 3 & $\begin{array}{l}\text { Kampanyalara katılım Hakkında Bilgiler (Kurumsal } \\
\text { Sosyal Sorumluluk, Yarışma gibi kampanya duyurusu }\end{array}$ & Var & Var & Var \\
\hline 4 & $\begin{array}{l}\text { Takipçilerin Hizmetler Hakkında Verdiği Yararlı } \\
\text { Bilgiler }\end{array}$ & Yok & Yok & Yok \\
\hline \multirow[t]{3}{*}{5} & $\begin{array}{l}\text { Kurumda Kariyer Olanakları Hakkında Bilgilendirme } \\
\text { Tweetleri/Paylașımları }\end{array}$ & Var & Var & Yok \\
\hline & Yüzde & $\% 60$ & $\% 60$ & $\% 40$ \\
\hline & Medya İçin Bilginin Yararlılığı Boyutu & & & \\
\hline 1 & Basın Bültenleri & Var & Var & Var \\
\hline 2 & Medya İçin Haber Niteliği Taşıyan Bilgiler & Var & Var & Var \\
\hline 3 & Konuşmalar & Var & Var & Var \\
\hline 4 & İndirilebilir Bilgi ve Grafikler & Var & Var & Var \\
\hline 5 & Görüntülü ve Sesli İçerikler & Var & Var & Var \\
\hline \multirow[t]{3}{*}{6} & $\begin{array}{l}\text { Yıllık Raporlar, Kurum Politikaları ve İş Ortakları } \\
\text { Hakkında Bilgi }\end{array}$ & Var & Var & Var \\
\hline & Yüzde & $\% 100$ & $\% 100$ & $\% 100$ \\
\hline & $\begin{array}{l}\text { Bilginin Kullanışlılığ1 Kategorisi Standart Sapma } \\
\text { Toplam Yüzde }\end{array}$ & $\% 83$ & $\% 87$ & $\% 76$ \\
\hline
\end{tabular}

Çalışmanın bir diğer kategorisi yeniden ziyareti sağlama kategorisidir. Bu kategoride sosyal medya hesaplarına takipçilerin yeniden ziyaretini sağlamalarına yönelik yaptıkları paylaşımları değerlendirmek amacıyla kategoriler oluşturulmaktadır. Buna göre Twitter \%57, Facebook \%29, Instagram \%43 olarak kayıt altına alınmıştır. Bakanlığın Twitter hesabının Yeniden ziyareti sağlama kategorisini orta düzeyde gerçekleştirdiği görülmektedir. Facebook ve Instagram hesapları ise bu kategoriyi düşük düzeyde gerçekleştirmektedir. Bu noktada kamu kuruluşu olarak ziyaretçilerin tekrar ziyaretini sağlama konusunda bir çaba kaydedilmediği söylenebilir. Daha fazla bilgi için kurumun web sitesindeki ilgili sayfalara linklere ilişkin gönderi örneği Resim 3 olarak aşağıdaki bölümde verilecektir. 
Tablo 3. Yeniden Ziyareti Sağlama Kategorisi

\begin{tabular}{lccc}
\hline Yeniden Ziyareti Sağlama Kategorisi & Twitter & Facebook & Instagram \\
\hline Daha Fazla Bilgi İçin Kurumun Web Sitesindeki Sayfalara Linkler & Var & Var & Var \\
Kurum Etkinliklerini Anlatan Kurumun Web Sitesindeki İlgili Sayfaya Linkler & Var & Var & Var \\
Kurum hakkında Yararlı Bilgi İçeren Sayfalara Linkler & Var & Yok & Var \\
Ticari veya Ana Akım Medyada Kurum Hakkında Çıkan Haberlere Linkler & Yok & Yok & Yok \\
Tartışma Forumlarına ve Kurumun Web sitesindeki SSS sayfasına Linkler & Yok & Yok & Yok \\
Takipçi Olmayanlara Kurumun Hesabını Takip Etmeleri İçin Çağrı & Yok & Yok & Yok \\
Kurumun Gelecekteki Olay Takvimine İlişkin Tweet Mesajları/Paylaşımları & Var & Yok & Yok \\
\hline Yüzde & $\% 57$ & $\% 29$ & $\% 43$ \\
\hline
\end{tabular}

Ziyaretçilerin elde tutulması kategorisinde yer alan dört ayrı alt kod için gerçekleştirilen kayıt sonrasında elde edilen verilere göre Twitter, Facebook ve Instagram hesaplarının \%100 oranında alt kategorilerde paylaşım yaptığı kayıt altına alınmıştır. Ziyaretçilerin elde tutulması kategorisinin yüksek düzeyde gerçekleştiğini söylemek mümkündür. Tüm hesaplardan diğer sosyal medya hesaplarına link verilmektedir. Twitter hesab1 üzerinden@sagliklicozum adresine, Facebook üzerinden https://twitter.com/saglikbakanligi adresine ve Instagram üzerinden@sbsagliklicozum Instagram adresine link verilmiştir. Buna göre kurumun diğer sosyal medya hesaplanna verilen linkler kategorisinde yer alan gönderilere örnek tabloların alt kısmındaki bölümde Resim 4 olarak verilmiştir.

Tablo 4. Ziyaretçilerin Elde Tutulması Kategorisi

\begin{tabular}{|c|c|c|c|}
\hline Ziyaretçilerin Elde Tutulması Kategorisi & Twitter & Facebook & Instagram \\
\hline Kurumun Diğer Sosyal Medya Hesaplarına Verilen Linkler & Var & Var & Var \\
\hline Kurumun Hizmetleri Hakkında Bilgi İçeren Kurum Web Sitesindeki İlgili Sayfaya & Var & Var & Var \\
\hline Kurum Profilinin İlk Sayfasındaki Son Mesajın 24 Saat İçinde Gönderilmiş Olması & Var & Var & Var \\
\hline Fotoğraf ve/veya Video Paylaşma & Var & Var & Var \\
\hline Yüzde & $\% 100$ & $\% 100$ & $\% 100$ \\
\hline
\end{tabular}

Diyalojik döngü kategorisinde ise her sosyal medya hesab1 12 sorudan 6'sinda var ifadesiyle kayıt altına alınmıştır. Buna göre Twitter, Facebook, Instagram hesaplarının diyalojik döngü kategorisi \%50 yüzde ile hesaplanmıştır. Kurumun bu noktada diyaloga orta düzeyde açık olduğu sonucuna ulaşıldığını söylemek mümkündür. Bu noktada kullanıcıların soru ve yorumlarına cevap verme kategorisinde, bakanlık sosyal medya hesaplarından yapılan diğer yönlendirmeyle (@sagliklicozum, @sbsagliklicozum vs) gerçekleştirilen soru ve yanıt gönderileri dikkate alınarak kayıt alına alınmıştır. Buna ilişkin örnek olarak tabloların altında yer alan Resim 4 örnek olarak verilmiştir. Analizin yapıldığı dönemde gerçekleşen İzmir depremine ilişkin paylaşımlar tüm sosyal medya hesaplarında kayıt altına alınmıştır. Ülke Gündemine İlişkin Paylaşımda Bulunmak kategorisine örnek olarak Resim 5 aşağıda yer almaktadır.

Tablo 5. Diyalojik Döngü Kategorisi

\begin{tabular}{llll}
\hline Diyalojik Döngü Kategorisi & Twitter & Facebook & Instagram \\
\hline Bakanlık Hakkında Diyalog Başlatmak İ̧̧in Takipçilere Soru Sormak & Yok & Yok & Yok \\
Kullanıcıların sorularına veya yorumlarına cevap verme & Var & Var & Var \\
Takipçilerin Eleştiri ve Şikâyetlerine Cevap Vermek & Var & Var & Var \\
Takipçilerin Diğer Konularda sorularına veya yorumlarına cevap vermek & Var & Var & Var \\
Takipçilere Hesapta ya da Paylaşılan İçerik Yoluyla Verilmiş Bir Dış Link & Yok & Yok & Yok \\
Takipçileri Kurum Temsilcisi İle İletişim Kurmaya Teşvik Etmek & Var & Var & Var \\
Takipçilerin Kurumla İlgili Bir Konuda Anket ya da Araştırmaya Katılmalarını & Yok & Yok & Yok \\
Takipçileri kendi içeriklerini göndermeleri konusunda teşvik etmek (video, & Yok & Yok & Yok \\
Takipçilerin Mesajlarını Paylaşmak & Yok & Yok & Yok \\
Ülke Gündemine İlişkin Paylaşımda Bulunmak & Var & Var & Var \\
Ülke Gündemine İlişkin Tartısmaya Katılmak & Yok & Yok & Yok \\
Gündemi Oluşturan Hastaghlere Link Vermek & Var & Var & Var \\
\hline
\end{tabular}

Bilginin kullanışlılığı kategorisi kurumun kamuları için yararlı bilgiler içerikli paylaşım örneği aşağıda Resim 1'de yer almaktadır. Covid 19 ile mücadele kapsamında hazırlanana Covid-19 Sözlügü çalışması içinde yer alan İnkübasyon Süresinin tanımının yer aldığı içerik aşağıda görülmektedir. Gönderide aynı zamanda bakanlığın web adresine yönlendiren bir link daha verilmektedir. Bu örnek Twitter'dan alınmıştır. İnkübasyon süresi gibi tıp terimlerini kamuların anlayabileceği bir biçimde ifade eden bu gönderiler 
takipçiler için yararlı bilgiler halinde sunulmaktadır. Bu nedenle takipçilere dönük yararlı bilgiler kategorisi içinde bu ve benzer gönderiler yer almaktadır.





Aşağıda yer alan örnekte bilginin kurum kamuları için yararlıllı̆̆ kategorisinde yer alan kariyer olanakları hakkında bilgilendirme kategorisine örnek olarak kayıt altına alınmıştır. Analizin gerçekleştiği dönemde alınacak olan 12 bin sağlık personeline ilişkin genel bir duyuru niteliği taşıyan gönderi Facebook'tan elde edilmiştir. Bu tip bir paylaşım Twitter'da da kayıt altına alınırken, Instagram'da ilgili tarihlerde bu tip bir gönderiye rastlanmamıştır.

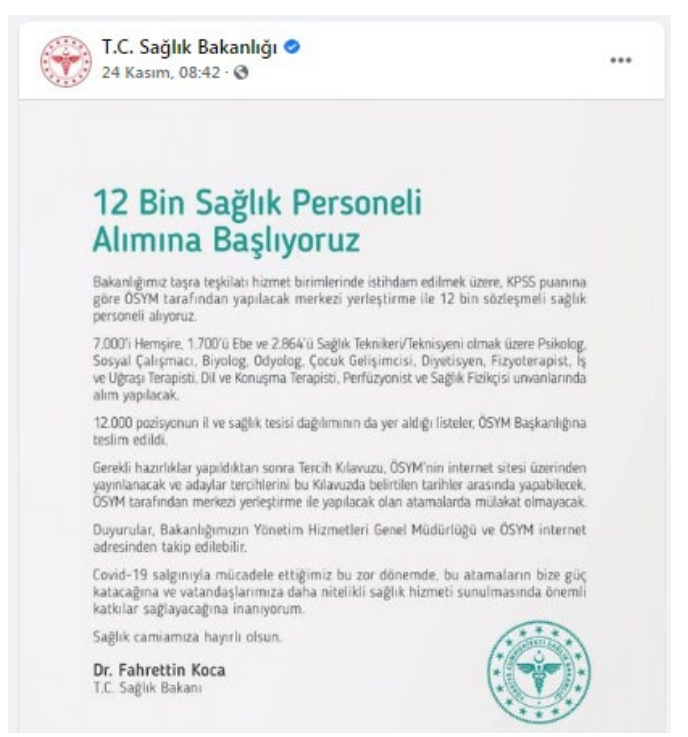

Resim 2. Bilginin Yararlhl̆ğ Kategorisi - Kurumda Kariyer Olanaklarn Hakekında Bilgilendirme Tweetleri/Paylaşmlar Örneği Facebook

Aşağıda yer alan Resim 3 örneğinde olduğu gibi kurumun resmi Facebook sayfasında kurumun web sayfasına verilen link gönderide yer almaktadır. Yeniden ziyareti sağlama kategorisinin "Daha Fazla Bilgi Iç̧in Kurumun Web Sitesindeki Sayfalara Linkler" alt koduna kaydedilen bu örnekte kullanıcılar detaylı bilgi için bakanlığının alternatif web sayfasına yönlendirilmektedir. Bu örnek kurumun Facebook sayfasından alınmıştır. 


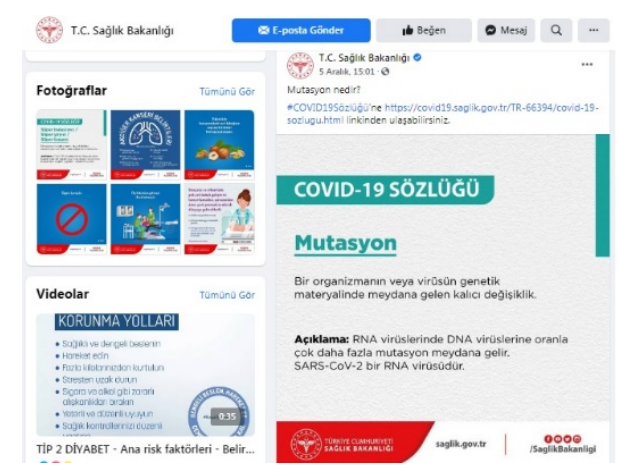

Resim 3. Daha Fą̧la Bilgi İ̧̧in Kurum Web Sayfasina Verilen Link Örneğğ-Facebook

Resim 4'te kurumun diğer sosyal medya hesaplarına verilen link örneği Facebook üzerinden takipçilere “T.C. Sağllk Bakanllğı Twitter'da https://twitter.com/saglikbakanligi” mesajıyla diğer bir sosyal medya hesabına link vererek takipçileri bilgilendirme amacı güdüldügü görülmektedir. Twitter ve Instagram sayfasından Facebook sayfasına her hangi bir yönlendirme kaydedilmemiştir. Diğer sosyal medya hesabına yönlendirme sadece Facebook sayfasında görülmektedir. Ancak diğer sosyal medya hesab1 olarak@sagliklicozum gibi alternatif hesaplara yönlendirme olduğu da bu noktada belirtilmelidir.



Resim 4. Kurumun Diğer Sosyal Medya Hesaplarna Verilen Linkler Örneği-Facebook

Diyalojik döngü kategorisinde yer alan ülke gündemine ilişkin paylaşımda bulunmak alt kategorisine örnek olarak analizin gerçekleştirildiği döneme denk gelen İzmir depremine ilişkin bir tweet örneği Resim 5'te yer almaktadır. Aynı zamanda Dr. Fahrettin Koca'nın resmi Twitter hesabından paylaşılan İzmir depremine ilişkin gönderilerin kurumun hesabından tekrar paylaşıldığı görülmektedir.

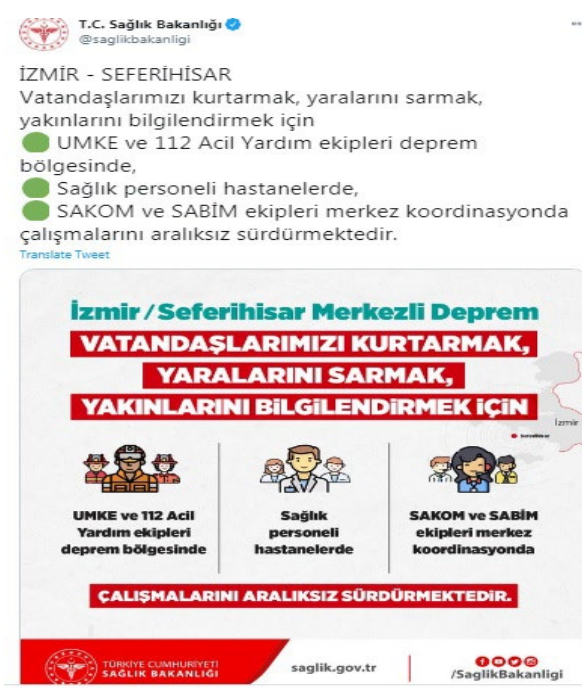

Resim 5. Diyalojik Döngü Kategorisi - Ülke Gündemine Illişkin Paylaşım - Twitter Örneği 
Aşağıda Resim 6’da görülen örnekte, takipçilerin öneri ve şikâyetlerine yanıt vermek kategorisinde Twitter hesabının künye kısmında “Öneri ve şikâyetlerinizi @sagliklicozum hesabına iletebilirsiniz.” ifadesi bulunmaktadır. Hesap künyesinden linklenen hesapta kullanıcı etkileşimleri bulunduğu kayıt altına alınmıştır. Aşağıda@sagliklicozum hesabından alınmış bir örnek yer almaktadır. T.C. Sağlık Bakanlığı hesabından yönlendirilen takipçilerin mesajlarına bu hesap üzerinden yanıt sağlanmaktadır.

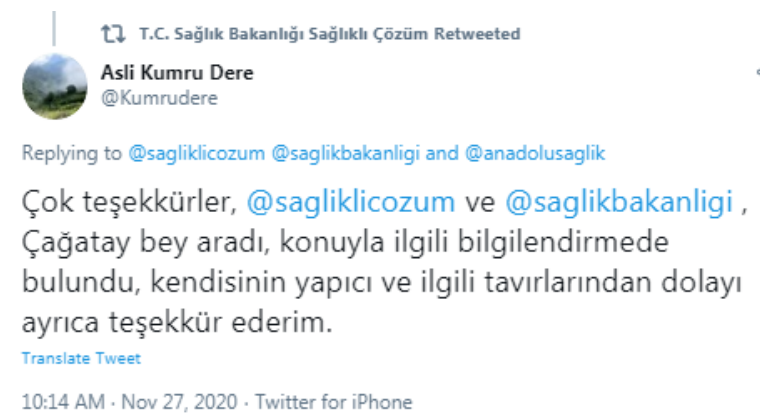

\section{Resim 6. Takipsilerin Eleștiri ve Şikâyetlerine Cevap Vermek Kategorisi Örneği - Twitter Örneği}

Diğer yandan Instagram hesabında “Öneri ve şikâyetlerinizi@sbsagliklicozum hesabına iletebilirsiniz." ifadesi yer almaktadır. Ancak hesap analiz tarihinden en yakın 5 hafta önce gönderi paylaşmış olarak kayıt altına alınmıştır. Hesap bu bağlamda "pasif" olarak değerlendirilmiştir.

\section{Tartışma, Sonuç ve Öneriler}

Halkla ilişkiler kavramının doğası gereği diyaloga açık olması gereklidir. Grunig ve Hunt'ın (1984) halkla ilişkiler modelleri tarihsel bir sınıflama ile değerlendirdiği bölümde, mükemmel halkla ilișkilere toplum ve kurum arasında simetrik bir iletişimin gerçekleştiği zaman ulaşılabileceği belirttiği bilinmektedir. Kent ve Taylor'un (1998) Diyalojk Halkla İlişkiler ilkelerini incelerken de kurum ve kamuları arasında diyaloga dönük bir iletişim modelinin halkla ilişkiler için gereklilik olduğu görülmektedir.

Diyalog yaşamın her noktasında olduğu gibi kurumlar için de hedef kitle ile karşıllkklı gerçekleştirmesi gereken bir ilkeler bütünüdür. Bir kavram olarak diyalojik halkla ilişkiler çerçevesinde, dijitalleşen iletişim dünyasının görece-firsatlarından olan sosyal medya uygulamalarını kullanan kurumlar, diyalojik boyutuyla sosyal medyayı ne ölçüde kullandıkları önem kazanmıştır. Bu amaçla bu çalışma ile T.C. Sağlık Bakanlığı’nın sosyal medya hesaplarını bu ilkeler doğrultusunda ne boyutta diyalojik olarak kullandığı ele alınmıştır. Araştırmada kullanılan ölçek Kent ve Taylor'un diyalojik halkla İlişkiler ilkelerinden hareketle hazırladıkları web sitesi analizleri için değerlendirilmiş ve daha sonra sosyal medya uygulamalarında da değerlendirilen (Türkal ve Güllüpınar, 2016) ölçektir. Dört boyuttan faydalanılmıss olup bu boyutlar; bilginin kullanışıllığ boyutu, ziyaretçilerin elde tutulması boyutu, yeniden ziyareti sağlama boyutu ve diyalogsal döngü boyutudur. Bu ölçekte değerlendirilmeyen ancak değerlendirilmesi gerektiği düşünülen takipçilerin etkileşimleri de ölçek ile desteklenerek çalışma verilerinin değerlendirilmesi aşamasinda kullanılmaya çalışılmıstır.

Bakanlığın sosyal medya hesaplarını diyalojik boyutunun bilginin kullanışlilı̆ı kategorisinde toplam standart sapma ile Twitter \%76, Facebook \%87, Instagram ise \%86 olarak hesaplanmıştır. Buna göre "bilginin kullanışlılığı" kategorisinde bakanlı̆̆ın sosyal medya hesaplarının diyalolojik boyutunu yüksek düzeyde gerçekleştirildiğini söylemek mümkün olmaktadır. "Ziyaretçilerin elde tutulması" kategorisinde Twitter, Facebook ve Instagram hesaplarının \%100 oranında alt kategorilerde paylaşım yaptığı ve diyalojik boyutta bu kategoriyi yüksek düzeyde kayıt altına alınmıştır. "Yeniden ziyareti sağlama" kategorisinde ise Twitter \%57, Facebook \%29, Instagram \%43 olarak kayıt altına alınmıstır. Bu sonuçlara göre Bakanliğın Twitter hesabının "diyalojik boyutu" orta düzeyde Facebook ve Instagram hesaplarının ise bu kategoriyi düşük düzeyde gerçekleştirdiği görülmektedir. Diyalojik döngü kategorisinde ise Twitter, Facebook, Instagram hesaplarının \%50 ile orta düzeyde diyaloga açık olduğu sonucuna ulaşıldığını söylemek mümkündür.

Tüm kategorilerden elde edilen sonuçlara göre Diyalojik Halkla İlişkiler boyutuyla Twitter \%73, Facebook \%66 ve Instagram \%67 ile orta düzey üstü bir genel sonuçla değerlendirilmiştir. Buna göre bakanlık sosyal medya hesaplarının orta düzey üstünde diyalojik halkla ilişkilere açık olduğu söylenebilir. Buna göre T.C. Sağlık Bakanlığı sosyal medya hesapları aktif olarak kullanıldığı sonucuna ulaşılmıştır. Çalışmanın diyalojik döngü kategorisine ek olarak gerçekleştirilen diğer beğeni, yorum ve tekrar paylaşım 
sayıları analizine göre ise takipçilerin T.C. Sağllk Bakanlı̆̆ı'nın Twitter, Facebook ve Instagram gönderilerine ne ölçüde etkileşim gösterdiği sorularının yanıtları elde edilerek sonuçlandırılmıştır. Buna göre Twitter kullanıcılarının gönderi başına takipçi etkileşimlerinin Twitter ve Facebook takipçi rakamlarının birbirine çok yakın olmasına karşın beğeni, yorum ve tekrar paylaşım kategorisinde Twitter takipçilerinin Facebook takipçilerine oranla daha fazla etkileşim gösterdiği de kaydedilerek yanıtlanmıştır. Takipçilerin kurumun paylaştıkları gönderilere ilişkin gösterdikleri etkileşimlere ilişkin bir analiz yapmak ayrı bir çalışmanın konusu olarak değerlendirilebilir çünkü takipçilerin kimi gönderilere etkileşim açısından hassasiyet gösterdiği analiz yapılırken bir ön değerlendirme olarak kayıt altına alınmıstır.

Sonuç olarak diyalojik halkla ilişkiler açısından ele alındığında sosyal medya kamu kurum ve kuruluşlarında etkin olarak kullanılabilecek bir araç görünümündedir. Bu sebeple araştırma diyalojik ölçütleriyle ele alınabilir. Ancak bu araştırma kullanılan ölçeğin özellikle diyalojik döngü boyutunda takipçi, beğeni, yorum ve tekrar paylaşım etkinliklerinin de değerlendirilmesinin gerektiği düşünülmektedir. Diğer yandan diyalogsal döngü içinde yer alan 12 ölçütün her biri aynı değerde değildir. Örneğin "takipçilerin sorularına yanıt verilmesi" kategorisi ile "takipçilerin kendi içeriklerini göndermek" konusundaki kategorinin aynı kıymette değerlendirilmemesi gerektiği tartı̧maya açık bir alandır. Buna göre gelecek araştırmalarda kullanıcıların gönderilere beğeni, yorum ve tekrar paylaşım rakamlarının da bu ölçekte değerlendirilmesi çalışmalar için fayda sağlayacağı ve diyalogsal döngü kategorisinin yeni medyanın değişen ve dönüşen yapısına uygun hale getirilmesi gerektiği düşünülebilir. Bir diğer değerlendirme ise çalısmanın Covid 19 pandemisi döneminde yapılması nedeniyle sosyal medya hesaplarının etkin kullanıldı̆̆ bir dönem olarak değerlendirilebilir. Bu nedenle bu çalışmanın pandemi dönemi bittikten sonra da tekrarlanarak karşılaştırmalı bir analiz ile değerlendirilebileceği de düşünülmektedir.

\section{Etik Beyan}

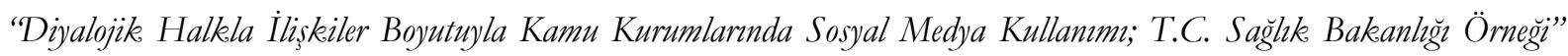
başlıklı çalışmanın yazım sürecinde bilimsel kurallara, etik ve alıntı kurallarına uyulmuş; toplanan veriler üzerinde herhangi bir tahrifat yapılmamış ve bu çalışma herhangi başka bir akademik yayın ortamına değerlendirme için gönderilmemiştir. Bu araştırmada doküman incelemesi yapıldığından etik kurul kararı zorunluluğu bulunmamaktadır.

\section{Kaynakça}

Arslan, C. (2019). An analysis of Instagram's dialogical communication building potential in Turkish theater institutions. Anadolu Üniversitesi Sanat ve Tasarm Dergisi, 9(1), 84-98.

Artan Özoran, B. (2017). Bir halkla ilişkiler ütopyası: diyalojik halkla ilişkiler. İstanbul Üniversitesi İletişim Fakültesi Dergisi, 53, 1-30.

Bergquist, M., Ljungberg, J., Remneland, B. ve Rolandsson, B. (2017). From e-government to e-governance: Social media and public authorities legitimacy work. Proceedings of The 25th European Conference on Information Systems (ECIS), 858-872.

Bilgin, N. (2006). Sosyal bilimlerde içerik analiz̧i teknikler ve örnek şalısmalar. Ankara: Siyasal Kitabevi.

Boztepe, H. (2013). Halkla ilişkilerin kurum ile hedef kitle arasında ilişki oluşturma amacı ve kurumsal web sayfalarının diyalojik halkla ilişkiler aracı olarak kullanımı. Akdeniz Üniversitesi İletişim Fakültesi Dergisi, 20,110-128.

Budak, G. ve Budak, G. (2014). Imaj mühendisliği vizyonundan halkla ilişkiler. Ankara: Nobel Yayıncilık.

Bulunmaz, B. (2015). Yeni medya eski medyaya karşı: savaşı kim kazandı ya da kim kazanacak? KTÜ İletişim Arastirmalar Dergisi, 4(7), 23-27.

Çelebi, E. (2019). Halkla ilişkiler uygulamalar nasıl olmah? Ankara: Nobel Yayınevi.

Duğan, Ö. ve Oğuz, A. (2018). Sosyal medyanın turizmde tanıtım amaçlı kullanımı: T.C. Kültür ve Turizm Bakanlığ1 örneği. Uluslararası Türk Dünyası Turiżm Arastırmalar Dergisi, 3(1), 1-13.

Erkek, S. (2016). Kamu kurumlarında sosyal medya kullanımı: Sağlık Bakanlığı örneği. Selcuk Üniversitesi Sosyal Bilimler Enstitüsü Dergisi, 2016(35), 141-150.

Facebook. (2020). T.C. Sağlık Bakanlığı. Erişim adresi. https://www.facebook.com/saglikbakanligi

Grunig, J. E. ve Hunt, T. (1984). Managing public relations. New York: Holt, Rinehart \& Winston.

Grunig, J. E. (2005). Halkla iliskiler ve iletişim yönetiminde mükemmellik. İstanbul: Rota Yayınları.

Instagram (2020). T.C. Sağlık Bakanlığı. Erişim adresi https://www.instagram.com/saglikbakanligi/

İşeri, K. Çapan Tekin, S. (2020). Küresel salgın dolayısıyla Sağlık Bakanı ve Bakanlığı tarafindan sosyal medyada paylaşılan görsel metinlerin çözümlenmesi. Turkish Studies, 15(6), 559-581.

Kalçık, T. ve Altan Bayraktar, Ü. (2020). Covid-19 salgınının yönetilmesinde sosyal medya kullanımı: Sağlık Bakanı Fahrettin Koca'nın resmi Twitter hesabı üzerine bir analiz. Turkish Studies, 15(6), 583-602.

Kalfa, M. ve Kocamaz-Adaş, S. (2019) Sosyal medyayı kullanım açısından Gençlik ve Spor Bakanlığının analizi. Türk Spor Bilimleri Dergisi, 2(1), 8-21. 
Kartal, N. Z., Dağ, H. ve Taşan. R. (2020). Bir kamu kurumu olarak Sağlık Bakanlığı'nın sosyal medya kullanımı: covid-19 süreci Youtube içerikleri üzerine bir inceleme. İçinde C. Arslan, E. Hamarta, S. Çiftçi, M. Uslu (Edt.) Akademik Araștırmalar 2020 (ss. 122-130). Konya: Çizgi Kitapevi.

Kent, M. L. ve Taylor, M. (1998). Building dialogic relationships through the world wide web. Public Relations Review, 24(3), 321-334.

Kent, M. L., ve Taylor, M. (2002). Toward a dialogic theory of public relations. Public Relations Review, 28(1), 21-37.

Leiva, Francisco M., Montoro Francisco J. ve Martınez, Teodoro L. (2006). Assessment of interjudge reliability in the open-ended questions coding process. Quality \& Quantity, 40, 519-537.

Mcnutt, K. (2012). Social media \& government 2.0. Kanada: University of Regina, Johnson-Shoyama Graduate School of Public Policy.

Özdemir, B. P. ve Aktaş Yamanoğlu, M. (2010). Türkiye'deki sivil toplum kuruluşları web sitelerinin diyalojik iletişim kapasiteleri üzerine bir inceleme. Ankyra: Ankara Üniversitesi Sosyal Bilimler Enstitüsü Dergisi, 1(2), 3-36.

Peltekoğlu, F. B. (2012). Halkla ilişkiler nedir? İstanbul: Beta.

Rybalko, S. ve Seltzer, T. (2010). Dialogic communication in 140 characters or less: how fortune 500 companies engage stakeholders using twitter. Public Relations Review, 36(4), 336- 441.

Seltzer, T. ve Mitrook, M. A. (2007). The dialogic potential of weblogs in relationship building. Public Relations Review, 33, 227-229.

Solis, B. ve Breakenridge, D. (2009). Putting the public back in public relations. New Jersey: FT Press.

Türk Dil Kurumu (2020). Sözlük. Erişim adresi https:/ / sozluk.gov.tr/

Türkal, İ. ve Güllüpunar, H. (2017). Diyalogsal halkla ilişkiler bağlamında sosyal medya kullanımı: Türkiye'de ilk 100'de yer alan şirketler üzerine bir inceleme. Gümüşhane Üniversitesi İletissim Fakültesi Dergisi, 5(2), 591-618.

Twitter (2020). T.C. Sağlık Bakanlığı. Erişim adresi https://twitter.com/saglikbakanligi

Yağmurlu, A. (2011). Kamu yönetiminde halkla ilişkiler ve sosyal medya. Selçuk İletişim Dergisi, 7(1), 5-15.

\section{EXTENDED ABSTRACT}

The subject of this study is to analyze the level of use of social networks by the Ministry of Health is for dialogical dimension with public. The purpose of this study is to identify the extent to which the Ministry of Health uses social media accounts in terms of interactive public relations. From this point of view, it aims to analyze the ministry's social media accounts with the scale of dialogical PR and bring this into literature. The fact that the work is relevant and based on the daily changing and evolving nature of the Internet points to the importance of research. First of all study includes dialogical public relations, and then the use of social networks in public institutions. After explaining the research method, the results are detailed and explained in the conclusion and discussion section.

Kent and Taylor (1998) mention five principles while adapting them on dialogic public relations websites. These principles; The dialogic cycle is listed as usefulness of information, providing revisiting, ease of interface, chatting with visitors. The scale, which was created to evaluate the dialogic dimension of social media created over these principles, was taken from Türkal and Güllüpınar's studies and used to analyze the Twitter, Facebook and Instagram accounts of the Ministry of Health. In addition to this, the number of posts, content likes, comments, reposts / re-tweets of the accounts analyzed within the specified period were also recorded. Follower interactions per post were also recorded and analyzed. Based on the fact that the importance of the research is up-to-date, the closest date to the research was chosen and the dates were determined for November 1-30, 2020. Research data were analyzed retrospectively for December 1-8, 2020. Accordingly, 453 content, including 218 on Twitter, 183 on Facebook, and 52 on Instagram, was included in the sample in order to obtain the basic data of social media accounts as well as the interaction rates.

Between November 1-30, 2020 when the analysis was carried out, 218 posts were shared on Twitter, 183 on Facebook, and 52 on Instagram. A total of 3,233,271 likes, 174,110 comments and 307,248 shares were recorded for 218 posts shared on Twitter. Based on this, the number of shares made by the account reached 14,832 likes, 799 comments, and 1,409 replays per post. A total of 183 posts were shared on Facebook and 436,587 likes, 13,791 comments, 29,343 repeat shares were recorded. Based on this point, the number of likes per post was calculated as 2,386, the number of comments 75 and the number of repeat shares during the mentioned period. In Instagram, a total of 52 posts were recorded as 624,143 likes, 11,030 comments and an average of 12,003 likes per post, and 212 comments per post. Since the Instagram application does not give back sharing opportunity within its own application, the number of back shares is not recorded in Instagram. Although the number of Twitter and Facebook followers is very close to each other, it has been observed that the number of likes, comments and shares per post differs. In the light of this data, it is possible to say that Twitter users are more sensitive than Facebook users in terms of likes, comments and reposting. 
Usefulness category of information; The profile information dimension is evaluated in sub-categories as the usefulness of information for public institutions and the usefulness of information for the media. Accordingly, the size of profile information was recorded as $89 \%$ for Twitter, $100 \%$ for Facebook, and $89 \%$ for Instagram. In the category of useful information for the publics of the institution, Twitter was determined as $40 \%$, Facebook $60 \%$ and Instagram $40 \%$. The last subcategory for media in the usefulness of information category was recorded as 100\%, Facebook 100\%, and Instagram $100 \%$ in the usefulness of information dimension. In the usefulness of information category, the total standard deviation was calculated as $76 \%$ for Twitter, $87 \%$ for Facebook and $86 \%$ for Instagram. Accordingly, it is possible to say that the social media accounts of the ministry are performed at a high level in the category of usefulness of information. Twitter was recorded as 57\%, Facebook 29\%, and Instagram 43\%. The Ministry's Twitter account has been found to perform in the Re-visit provision category at a medium level. According to the data obtained after the registration for four different sub-codes in the visitor retention category, it was recorded that Twitter, Facebook and Instagram accounts shared 100\% in sub-categories. It is possible to say that the retention of visitors category is realized at a high level. In the dialogic cycle category, every social media account is registered with the statement of answering 6 out of 12 questions.

From all these points, it can be said that the Ministry of Health openness to community has middle level in terms of dialogical public relations. On the other hand, it is thought that more comprehensive subcategories regarding user interactions should be added within the dimensions of dialogic public relations. 